\title{
FUZZY SUBJECTIVE EVALUATION OF ASIA PACIFIC AIRPORT SERVICES
}

\author{
Ku Ruhana Ku-Mahamud and Mahmod Othman \\ College of Arts and Sciences \\ Universiti Utara Malaysia \\ ruhana@uum.edu.my \\ Faculty of Information Technology and Quantitative Science \\ Universiti Teknologi MARA \\ math401@hotmail.com
}

\begin{abstract}
This paper presents a fuzzy decision-making model to determine the ranking of fourteen Asia Pacific airports based on the services provided to passengers. Airport services were represented by six attributes namely comfort, processing time, convenience, courtesy of staff, information visibility and security. Data for the attributes given by travel experts are in the triangular fuzzy number form. Based on fuzzy set and approximate reasoning, the model allows decision makers to make the best choice in accordance with human thinking and reasoning processes. The use of fuzzy rules which are extracted directly from the input data in making evaluation, contributes to a better decision and is less dependent on experts. Experimental results show that the proposed model is comparable to previous studies. The model is suitable for various fuzzy environments.
\end{abstract}

Keywords: Subjective Evaluation; Fuzzy Set; Approximate Reasoning.

\section{INTRODUCTION}

Evaluation of airport services is an important issue for management because it has a significant impact in promoting or discouraging future business activities for the country. Promoting the quality of services reflects the reputation of a company, product reliability and reduces the company's cost of expenditure. Most airports and other service organizations recognize the need to measure 
the levels of satisfaction and perceptions of service quality among their customers. Generally this involves asking customers for subjective attitudinal evaluations such as asking if they personally felt the service they received was satisfactory.

Service quality is a much more complicated term than it appears. There is no formal definition of service quality and a variety of perspectives can be taken in defining it. Service quality has been described by Parasuram, Zeithaml and Berry (1988) as a form of attitude which results from the comparison of expectations with performance. In other words, airport service quality can be defined as quality services offered by the airport operators towards meeting or exceeding customer expectations.

In practice, the evaluation of performance usually uses subjective criteria. In doing so, one has to depend on one's wisdom, experience, professional knowledge and information, which are difficult to define and/or describe accurately. When making an analysis using incomplete data, a lot of uncertainties will arise and this will confuse decision-makers and will complicate decision making as it is made under uncertain situations. The application of the fuzzy sets theory in evaluation systems can improve the evaluation results (Zhou, Ma \& Bolluju, 2002). Several researchers have tried to solve this problem through the analytical hierarchy process (AHP) where evaluation was done by aggregating all the fuzzy sets, for example, in personnel selection (Liang \& Wang, 2001; Sonja, 2001) and shipping performance (Chou \& Liang, 2001). However, the presence of imprecision, vagueness and subjectivity at each level further accumulates greatly the undesired elements in aggregating the marks.

A major advantage of the fuzzy modelling method is the use of linguistics to represent relationships being modelled instead of using quantitative variables of traditional methods. Linguistic or fuzzy variables are those with names that characterize the semantics of the underlying concept under consideration and these fuzzy variables are represented mathematically by fuzzy sets (Corne, Murray \& Turton, 1999). Fuzzy membership sets enable the interpretations of linguistic variables in a very natural and plausible way to formulate and solve various problems. However, expressing the linguistic variable using the singleton fuzzy sets could result in the loss of much important information and would additionally complicate the course of action. Concepts focusing on the combination of the fuzzy logic model with multi objective decisions that can assist in reducing errors in making a judgment have been proposed by Liang and Wang (2001) and Pedrycz and Gomide (1998). These studies provide approaches to judgment procedure on personnel selection through 
the development of the analytical hierarchy process based on fuzzy multi criteria. It is cited as being able to minimize subjectivity. Some studies in fuzzy evaluation methods are discussed in Othman, Ku-Mahamud \& Bakar (2004a; 2004b and 2004c). The authors have proposed algorithms based either on fuzzy similarity function or fuzzy synthetic decision and ranking procedure through satisfaction function.

Developments in the application of the fuzzy theory for environmental management have created new opportunities for the utilization of this theory for soil quality assessment (Baja, 2002; Kurtener \& Badenko, 2000a, 2000b; Torbert, Krueger, \& Kurtner, 2008). The results of these studies indicated that the fuzzy multi-attribute approach could be effectively utilized as a tool leading to a better understanding of soil quality. Muhammetoglu and Yardimci (2006) have developed a fuzzy logic approach to access the groundwaterpollution levels below agricultural fields. In this study, fuzzy logic approach has shown to be a practical, simple and useful tool to assess the groundwaterpollution levels.

A method based on the concept of the fuzzy set theory has been used for decision making by Singh, Dahiya, and Jain (2008) for the assessment of physic-chemical quality of ground water for drinking purposes. The application of the fuzzy rule-based optimization model is illustrated with twenty groundwater samples from the Sohna town of the Gurgeon district of Southern Haryana, India.

Although many evaluation methods for selecting or ranking have been suggested in the literature, there is so far no method which can give a satisfactory solution to every situation. In this paper, a model that incorporates fuzzy sets and approximate reasoning is used to determine the ranking of 14 major Asia-Pacific airports based on their services provided to passengers. This is done by computing the satisfaction value of the passenger services qualitative attribute. The results were compared to the original study done by Yeh and Kuo (2003) where an overall service performance index was determined based on the concept of optimality.

\section{CASE BACKGROUND}

Data on 14 Asia-Pacific international airports in Yeh and Kuo (2003) has been adopted and used in this study. Airport services were represented by six attributes namely the comfort, processing time, convenience, courtesy of staff, information visibility and security as depicted in Table 1 . These functional qualities play the most critical role in passenger's overall quality perception. 
Table 1

\section{Service Attributes}

\begin{tabular}{ll}
\hline Service Attribute & Performance Measure \\
\hline Comfort $\left(C_{l}\right)$ & $\begin{array}{l}\text { Cleanliness, lighting and congestion level of waiting } \\
\text { areas/lounges, and ambience of the airport as a whole. }\end{array}$ \\
Processing time $\left(C_{2}\right)$ & $\begin{array}{l}\text { Total time required for immigration processing, } \\
\text { customs inspection, and luggage claiming. } \\
\text { Availability/accessibility of washrooms, shops, } \\
\text { restaurants, money exchange, cash machines, } \\
\text { luggage carts, and rental facilities. }\end{array}$ \\
Convenience $\left(C_{3}\right)$ & $\begin{array}{l}\text { Helpfulness, friendliness and courtesy of airport } \\
\text { staff. }\end{array}$ \\
Information visibility $\left(C_{5}\right)$ & $\begin{array}{l}\text { Clearness and/or frequency of information display } \\
\text { for flights, airport facilities, and signposting. } \\
\text { Sense of security about airport safety measures and } \\
\text { security facilities. }\end{array}$ \\
\hline
\end{tabular}

The 14 airports indicated by their codes are listed in Table 2 together with the average fuzzy performance ratings given by travel experts. The values are in the range of 0 to 100 , represented as a triangular fuzzy number that can be defined as a triplet $\left(a_{1}, a_{2}, a_{3}\right)$, individually. Travel experts are tour operators in Taiwan who have visited all or almost all the 14 airports. Two sets of linguistic terms are used to evaluate the services of the airports. The first set is not important, somewhat important, important and extremely important $\}$ while the second set is \{very poor, poor, fair, good and very good\}. Triangular fuzzy numbers ranging between 0 and 100 were assigned to represent the linguistic terms.

Table 2

Average Fuzzy Performance Ratings Assessed by Travel Experts

\begin{tabular}{lcccccc}
\hline $\begin{array}{l}\text { International } \\
\text { Airport }\end{array}$ & $\mathbf{C}_{1}$ & $\mathbf{C}_{2}$ & $\mathbf{C}_{3}$ & $\mathbf{C}_{4}$ & $\mathbf{C}_{5}$ & $\mathbf{C}_{6}$ \\
\hline $\begin{array}{l}\text { Dong Muang } \\
\text { (BKK) }\end{array}$ & $(50,60,68)$ & $(51,60,68)$ & $(59,68,76)$ & $(33,48,65)$ & $(45,55,64)$ & $(50,62,70)$ \\
$\begin{array}{l}\text { Soekarno- } \\
\text { Hatta, (CGK) }\end{array}$ & $(42,56,67)$ & $(41,55,71)$ & $(56,65,74)$ & $(48,56,64)$ & $(61,68,78)$ & $(30,40,53)$ \\
\hline
\end{tabular}

(continued) 
Table 2

Average Fuzzy Performance Ratings Assessed by Travel Experts

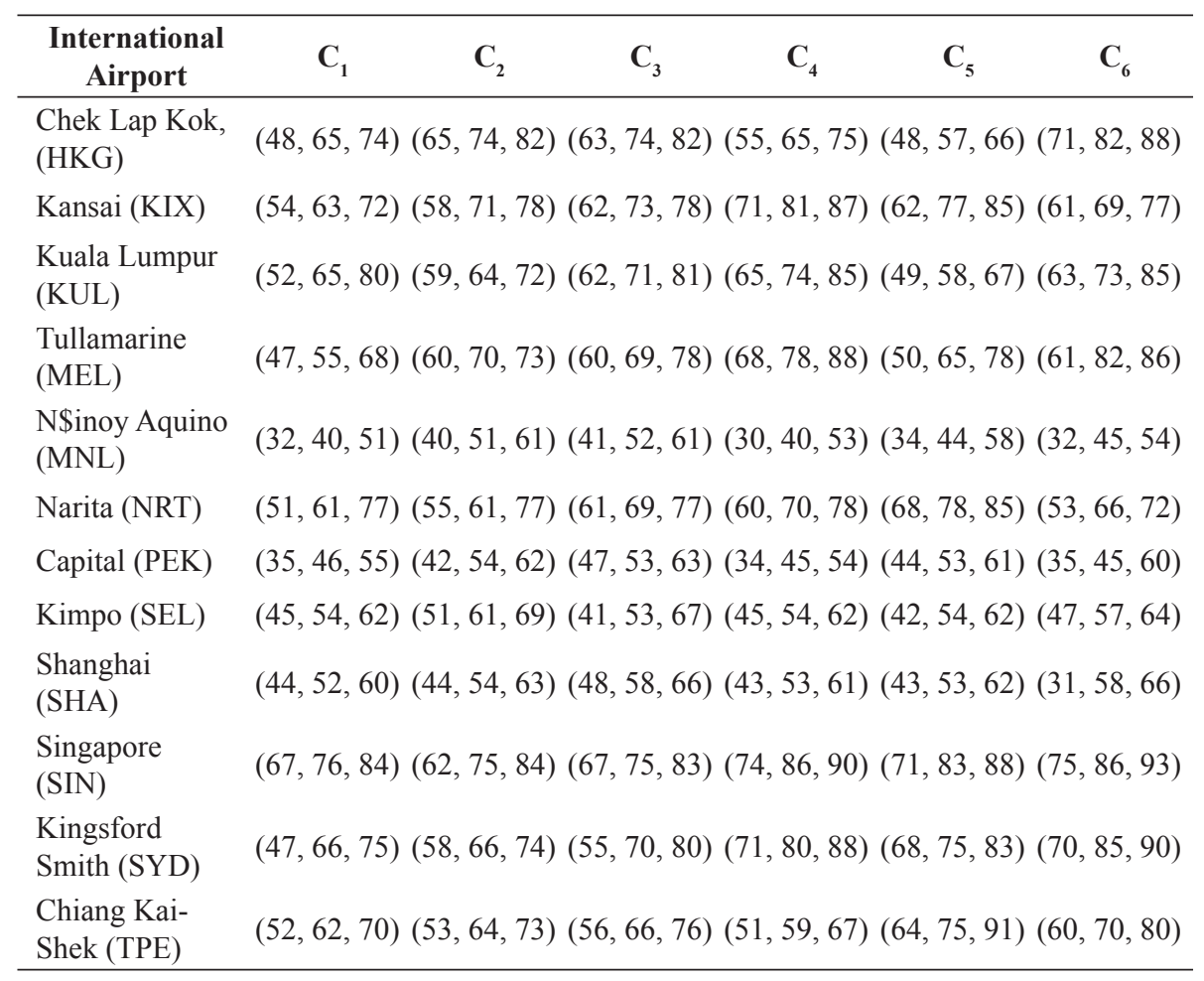

PROPOSED FUZZY EVALUATION MODEL

The proposed model is based on the work done by Biswas (1995) and Chu (1990) on the use of similarity function and synthetic decision-making. However, this model focuses on extracting rules and membership set score from data which is different from the works of Biswas (1995) and Chu (1990).

There are nine steps in the proposed model for evaluating the service performance of the airports. The first step is to transform the input data into membership set score. The grade mid-point and mid-interval marks are then identified followed by the determination of the fuzzy membership set and fuzzy set grade. Calculation of the similarity value is taken in the fifth step and this is followed by the calculation of the normalized synthetic score value. The last three steps in this proposed model deal with the evaluation of the attribute rule value and the appraisal product value followed by the calculation of the satisfaction value. The ranking of the airport services is based on the obtained 
satisfaction value where the biggest value would indicate the airport with the best services.

Results of the transformation of the input into membership set score for service attribute $C_{l}$ of each airport are shown in Table 3.

Table 3

Membership Set Score for $C_{1}$

\begin{tabular}{cccccccccccc}
\hline \multicolumn{10}{c}{$\boldsymbol{C}_{\mathbf{1}}$} \\
\hline Airport & $\mathbf{0}$ & $\mathbf{1 0}$ & $\mathbf{2 0}$ & $\mathbf{3 0}$ & $\mathbf{4 0}$ & $\mathbf{5 0}$ & $\mathbf{6 0}$ & $\mathbf{7 0}$ & $\mathbf{8 0}$ & $\mathbf{9 0}$ & $\mathbf{1 0 0}$ \\
BKK & 0 & 0 & 0 & 0 & 0 & 0 & 1.00 & 0 & 0 & 0 & 0 \\
CGK & 0 & 0 & 0 & 0 & 0 & 0.57 & 0.64 & 0 & 0 & 0 & 0 \\
HKG & 0 & 0 & 0 & 0 & 0 & 0.12 & 0.71 & 0.44 & 0 & 0 & 0 \\
KIX & 0 & 0 & 0 & 0 & 0 & 0 & 0.67 & 0.22 & 0 & 0 & 0 \\
KUL & 0 & 0 & 0 & 0 & 0 & 0 & 0.62 & 0.62 & 0 & 0 & 0 \\
MEL & 0 & 0 & 0 & 0 & 0 & 0.38 & 0.62 & 0 & 0 & 0 & 0 \\
MNL & 0 & 0 & 0 & 0 & 1.00 & 0.10 & 0 & 0 & 0 & 0 & 0 \\
• & & & & & & & & & & & \\
TPE & 0 & 0 & 0 & 0 & 0 & 0 & 0.80 & 0 & 0 & 0 & 0 \\
\hline
\end{tabular}

Grade was used to feed the model with knowledge. In this study, grades are represented by the letters "A", "B", "C", "D" and "E". The mid-point and the mid-intervals for each grade are determined as illustrated in Table 4. This notion of mid-point for the range was introduced by Tucksen and Wilson (1994). The construction of the fuzzy membership set is undertaken in the third step as shown in Table 5 where each row represents a fuzzy membership set. The standard grade fuzzy set is then defined, as practised by Biswas (1995) as shown in Table 6 .

Table 4

Grade Mid-Point and Mid-Interval Mark

\begin{tabular}{cccc}
\hline Grade & Range & Mid-Point & Mid-Interval \\
\hline A & $90.0-100.0$ & 95.0 & $92.5,97.5$ \\
B & $70.0-90.0$ & 80.0 & $75.0,85.0$ \\
C & $50.0-70.0$ & 60.0 & $55.0,65.0$ \\
D & $30.0-50.0$ & 40.0 & $35.0,45.0$ \\
E & $00.0-30.0$ & 15.0 & $7.5,22.5$ \\
\hline
\end{tabular}




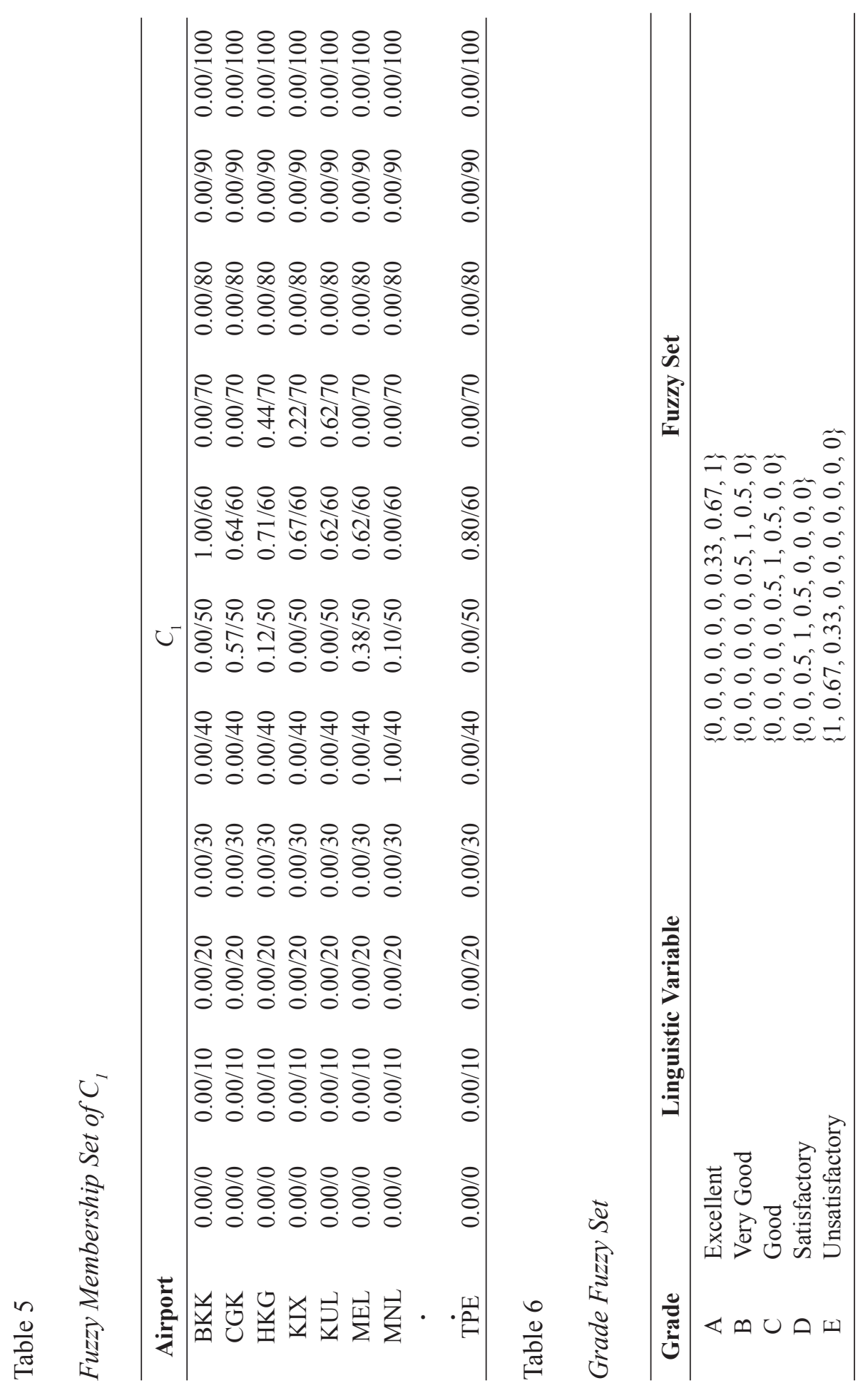


Normalization of the input data which is undertaken in the fifth step involves the calculation of the similarity value and determining the grade for each criterion. Similarity value, $S(F, M)$, is calculated as follows:

$$
\mathrm{S}(F, M)=\frac{\hat{F} \cdot \hat{M}}{\max (\hat{F} \cdot \hat{F}, \hat{M} \cdot \hat{M})},
$$

where $\hat{F}=\left(\mathrm{m}_{\mathrm{F}}\left(\mathrm{x}_{1}\right),\left(\mathrm{m}_{\mathrm{F}}\left(\mathrm{x}_{2}\right), \ldots\right), \hat{M}=\left(\mathrm{m}_{\mathrm{M}}\left(\mathrm{x}_{1}\right),\left(\mathrm{m}_{\mathrm{M}}\left(\mathrm{x}_{2}\right), \ldots\right)\right.\right.$ are the vectors and $M$ denotes the transpose vectors grade fuzzy set $A^{T}, B^{T} C^{T}, D^{T}$ and $E^{T} . \hat{F}$ represents the transpose vector of fuzzy set $f_{i j}$. Set $X=\left(x^{1}, x^{2}\right.$, $\ldots, x_{n}$ ) represents the set of universe of discourse and '.' is the dot product. The similarity values for airport BKK is presented in Table 7.

Table 7

Similarity Value

\begin{tabular}{cccccccc}
\hline Airport & Grade & $\boldsymbol{C}_{\mathbf{1}}$ & $\boldsymbol{C}_{\mathbf{2}}$ & $\boldsymbol{C}_{\mathbf{3}}$ & $\boldsymbol{C}_{\mathbf{4}}$ & $\boldsymbol{C}_{\mathbf{5}}$ & $\boldsymbol{C}_{\mathbf{6}}$ \\
\hline BKK & $\mathrm{A}$ & 0 & 0 & 0 & 0 & 0 & 0 \\
& $\mathrm{~B}$ & 0.33 & 0.33 & 0.54 & 0.1 & 0.15 & 0.28 \\
& $\mathrm{C}$ & 0.67 & 0.67 & 0.32 & 0.49 & 0.46 & 0.55 \\
& $\mathrm{D}$ & 0 & 0 & 0 & 0.16 & 0 & 0 \\
& $\mathrm{E}$ & 0 & 0 & 0 & 0 & 0 & 0 \\
\hline
\end{tabular}

The maximum similarity value is determined by identifying the maximum of the similarity values in Table 7. Table 8 displays the maximum similarity value, grade and fuzzy mark for airport BKK. Maximum similarity values of Table 8 are used as input to develop normalized synthetic score value as shown in Table 9.

Table 8

Maximum Similarity Value

\begin{tabular}{lcccc}
\hline \multirow{2}{*}{ Airport } & Attribute & $\begin{array}{c}\text { Max Similarity } \\
\text { Value }\end{array}$ & Grade & Fuzzy Mark \\
\hline BKK & $C_{1}$ & 0.67 & $\mathrm{C}$ & 60 \\
& $C_{2}$ & 0.67 & $\mathrm{C}$ & 60 \\
& $C_{3}$ & 0.54 & $\mathrm{~B}$ & 80 \\
& $C_{4}$ & 0.49 & $\mathrm{C}$ & 60 \\
& $C_{5}$ & 0.46 & $\mathrm{C}$ & 65 \\
& $C_{6}$ & 0.55 & $\mathrm{C}$ & 65 \\
\hline
\end{tabular}


Table 9

Normalized Synthetic Score Value

\begin{tabular}{ccccccc}
\hline Airport & $\mathbf{C}_{\mathbf{1}}$ & $\mathbf{C}_{\mathbf{2}}$ & $\mathbf{C}_{\mathbf{3}}$ & $\mathbf{C}_{\mathbf{4}}$ & $\mathbf{C}_{5}$ & $\mathbf{C}_{\mathbf{6}}$ \\
\hline BKK & 0.60 & 0.60 & 0.80 & 0.60 & 0.65 & 0.65 \\
CGK & 0.60 & 0.60 & 0.70 & 0.60 & 0.70 & 0.40 \\
HKG & 0.65 & 0.75 & 0.75 & 0.65 & 0.65 & 0.85 \\
KIX & 0.65 & 0.75 & 0.75 & 0.8 & 0.80 & 0.70 \\
KUL & 0.65 & 0.70 & 0.75 & 0.80 & 0.60 & 0.75 \\
MEL & 0.55 & 0.75 & 0.75 & 0.85 & 0.65 & 0.80 \\
MNL & 0.40 & 0.50 & 0.55 & 0.40 & 0.45 & 0.45 \\
$\cdot$ & & & & & & \\
$\cdot$ & & & & & & \\
TPE & 0.60 & 0.55 & 0.70 & 0.60 & 0.75 & 0.70 \\
\hline
\end{tabular}

The decision criteria, $D C_{i}, i=1,2,3, \ldots, 5$, is the intersection or combination of fuzzy rules which is the antecedent of the rule (refer to Table 10). The combination multi-criteria rules described in Table 10 can be generalized as follows:

$$
\text { If }\left(D C_{i}=\bigcap_{j=1}^{6} \cup \mathrm{C}_{j}\right) \text { then } A_{\mathrm{k}}
$$

where $D C_{i}$ is the decision criteria, $C_{j}$ is the attribute rule, $A_{\mathrm{k}}$ is the linguistic variable and $\mathrm{k}$ represents the grade. For example, the decision criteria $C_{1}$ rule can be written as:

$$
\text { If } D C_{1}=C_{1} \cap C_{4} \text { then } A_{1} \text { satisfactory } A_{1}(v)=v \text {, }
$$

The appraisal set, $v$, is defined as, $v=\{0,0.1,0.2,0.3,0.4,0.5,0.6,0.7,0.8$, $0.9,1\}$ where $v$ is unit appraisal space in $[0,1]$.

The rule value in Table 11 is obtained by processing the normalized synthetic score value according to the multi-criteria decision of Table 10 . 
Table 10

Multi Criteria Rules Combination

\begin{tabular}{clccc}
\hline $\begin{array}{c}\text { Decision } \\
\text { Criteria }\end{array}$ & Attribute Rule & Linguistic Variable & Description & $\begin{array}{c}\text { Appraisal } \\
\text { Set }\end{array}$ \\
\hline $\mathrm{DC}_{1}$ & $C_{1} \cup C_{4}$ & $A_{1}$ & Satisfactory & $v$ \\
$\mathrm{DC}_{2}$ & $C_{1} \cap C_{2} \cap C_{6}$ & $A_{1}$ & Satisfactory & $v$ \\
$\mathrm{DC}_{3}$ & $C_{1} \cap C_{2} \cap C_{4}$ & $A_{1}$ & Satisfactory & $v$ \\
$\mathrm{DC}_{4}$ & $C_{6}$ & $A_{1}$ & Satisfactory & $v$ \\
$\mathrm{DC}_{5}$ & $C_{1} \cup C_{4}$ & $A_{1}$ & Satisfactory & $v$ \\
\hline
\end{tabular}

Table 11

Attribute Rule Value

\begin{tabular}{crrrrr}
\hline \multicolumn{5}{c}{ Attribute } \\
\hline Airport & $\boldsymbol{C}_{1}$ & $\boldsymbol{C}_{2}$ & $\boldsymbol{C}_{3}$ & $\boldsymbol{C}_{4}$ & $\boldsymbol{C}_{5}$ \\
BKK & 0.6000 & 0.6000 & 0.6000 & 0.6500 & 0.6000 \\
CGK & 0.6500 & 0.6000 & 0.6000 & 0.4000 & 0.6500 \\
HKG & 0.6500 & 0.7000 & 0.7000 & 0.8500 & 0.7000 \\
KIX & 0.8500 & 0.6000 & 0.6000 & 0.8000 & 0.8500 \\
KUL & 0.6000 & 0.7000 & 0.7000 & 0.8000 & 0.7500 \\
MEL & 0.6000 & 0.6000 & 0.6000 & 0.8000 & 0.8500 \\
MNL & 0.4500 & 0.4500 & 0.4500 & 0.4500 & 0.4500 \\
$\cdot$ & & & & & \\
TPE & 0.6000 & 0.6000 & 0.6000 & 0.7000 & 0.6000 \\
\hline
\end{tabular}

The appraisal fuzzy value of Table 12 for the decision criteria is computed as follows [4]:

$$
d_{j}(m, l)=1 \wedge\left(1-\widetilde{c}\left(u_{m}\right)+A_{k}\left(v_{l}\right)\right.
$$

where $j=1,2,3, \ldots, 5, m=1,2,3, \ldots, 5, l$ is the number of appraisal in $V$ and is given by $l=1,2, \ldots, 11$ and $\widetilde{c}\left(u_{m}\right)_{\mathrm{i}}$ s the difference of attribute rule value from one unit. This is followed by the computation of the appraisal product value, $\mathrm{D}$, using the formulae $\mathrm{D}=\prod_{j=1}^{5} d_{j}(m, l)$ The appraisal product values for the airports are shown in Table 13. 


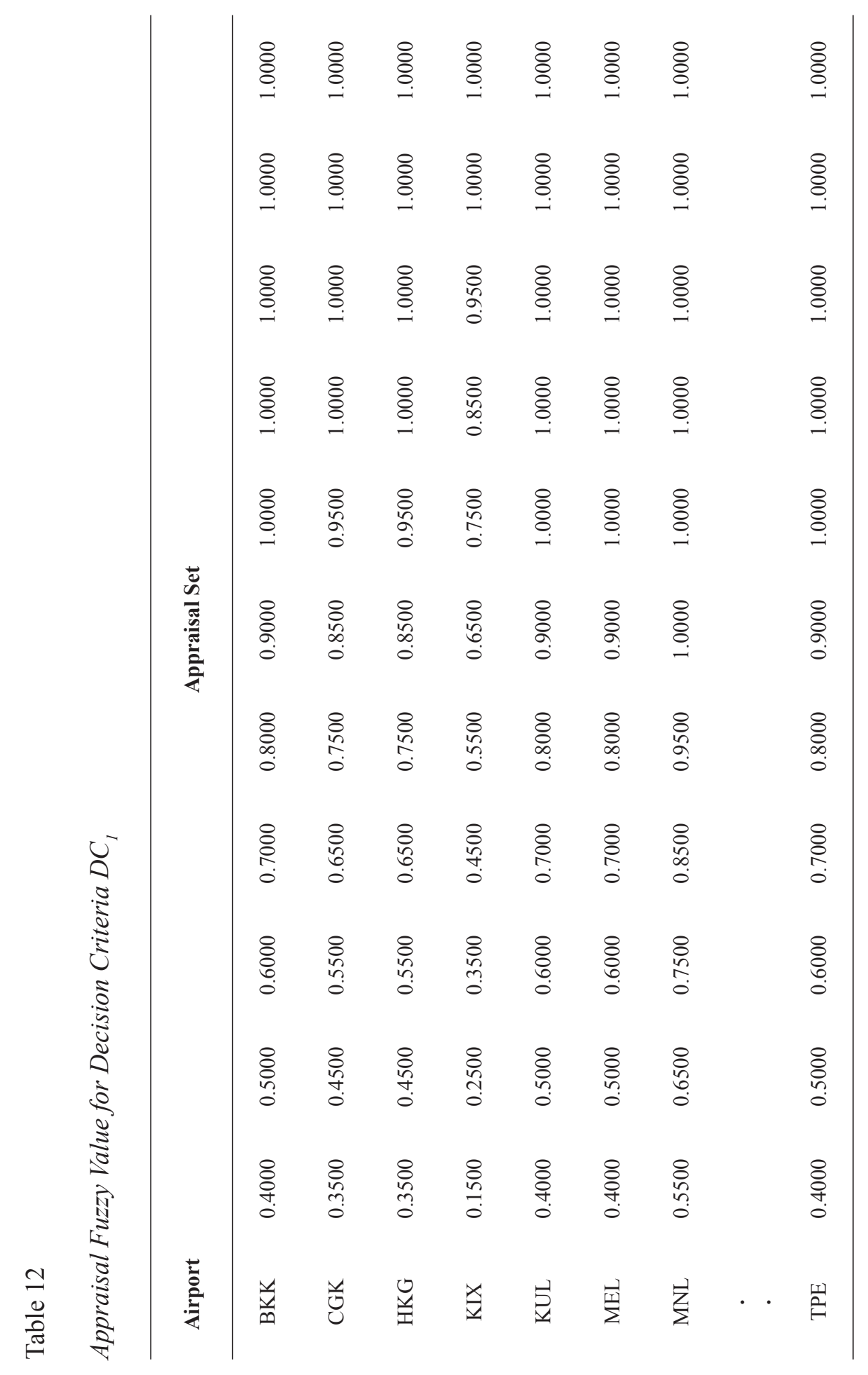


Table 13

Appraisal Product Value

\begin{tabular}{ccccccccc}
\hline Airport & \multicolumn{7}{c}{ Appraisal Set } \\
\hline BKK & 0.0090 & 0.0281 & 0.0713 & $\ldots$ & 1.0000 & 1.0000 & 1.0000 \\
CGK & 0.0118 & 0.0354 & 0.0871 & $\ldots$ & 1.0000 & 1.0000 & 1.0000 \\
HKG & 0.3000 & 0.4000 & 0.5000 & $\ldots$ & 1.0000 & 1.0000 & 1.0000 \\
KIX & 0.1500 & 0.2500 & 0.3500 & $\ldots$ & 0.9500 & 1.0000 & 1.0000 \\
KUL & 0.2500 & 0.3500 & 0.4500 & $\ldots$ & 1.0000 & 1.0000 & 1.0000 \\
MEL & 0.1500 & 0.2500 & 0.3500 & $\ldots$ & 0.9500 & 1.0000 & 1.0000 \\
MNL & 0.5500 & 0.6500 & 0.7500 & $\ldots$ & 1.0000 & 1.0000 & 1.0000 \\
• & & & & & & & \\
TPE & 0.4000 & 0.5000 & 0.6000 & $\ldots$ & 1.0000 & 1.0000 & 1.0000 \\
\hline
\end{tabular}

Performance can be ranked using the satisfaction value, $S V(m)$, as given below:

$$
S V(m)=\frac{1}{\alpha_{\max }} \sum_{l=1}^{1} H_{l}\left(E_{m \alpha}\right) \Delta \alpha_{l}
$$

where $\alpha=$ degree of appraisal product value, $\Delta \alpha_{l}=\alpha_{l}-\alpha_{l-1}, \alpha_{0}=0$, $H_{l}\left(E_{m \alpha}\right)=$ mid-point $\mathrm{V}_{l}(l=1,2,3 \ldots, 11)$ and $\alpha_{\max }=$ maximum degree of appraisal product value. The calculated values of the range of $\alpha, \Delta \alpha_{l}$, and $H_{l}\left(E_{m \alpha}\right)$ are tabulated in Table 14.

The highest satisfaction value is considered as the best performance which implies that the experts are much more satisfied with the airport service as discussed in Lee et al. (1994). 


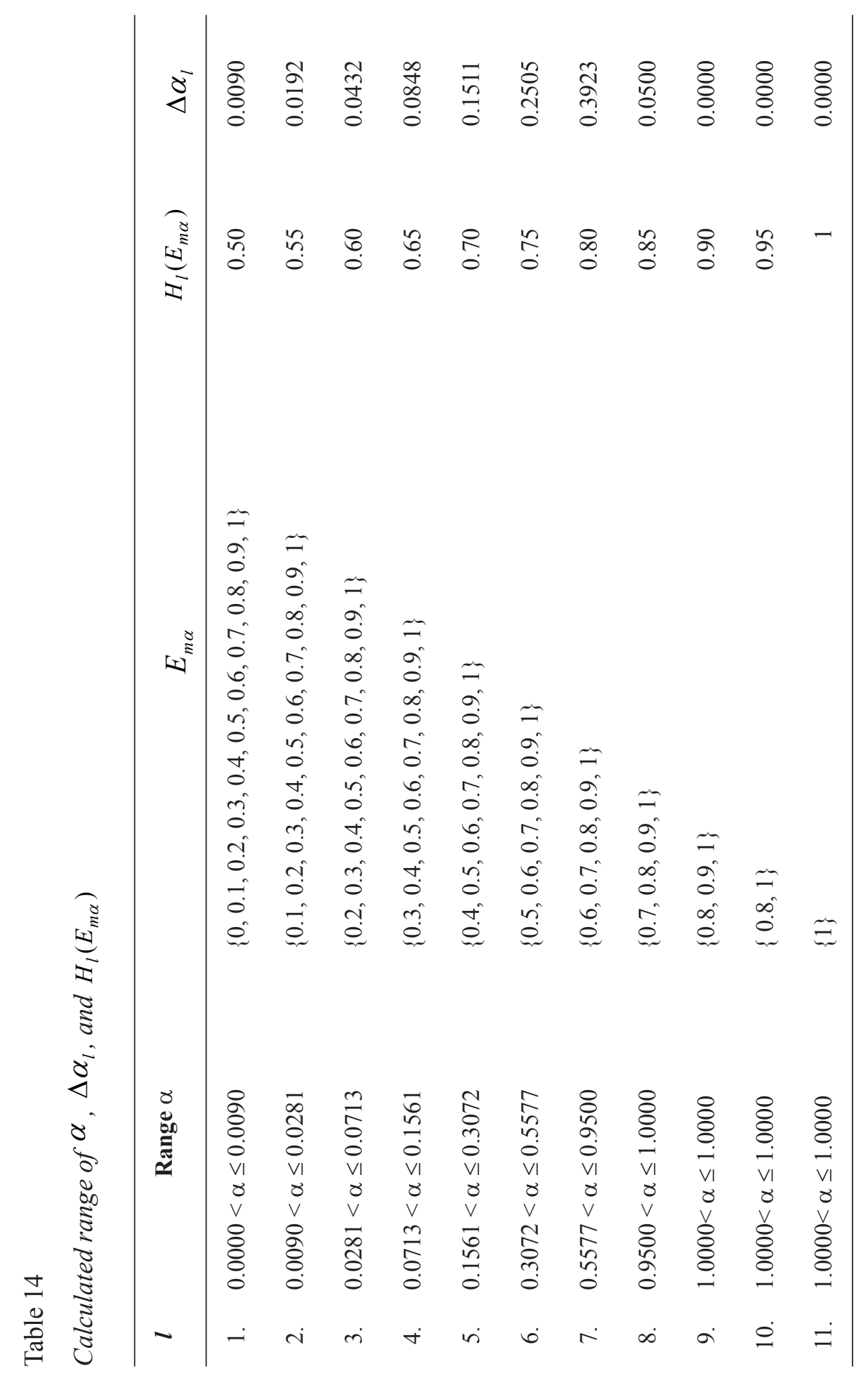




\section{NUMERICAL RESULTS}

Comparison of results between Yeh and Kuo (2003) and the proposed model are depicted in Table 15 where airport services are ranked based on the satisfaction values. The experimental results show that the proposed model is comparable to Yeh and Kuo (2003). The model is in fact better because of the use of fuzzy rules in making a good ranking in accordance with human decision making (Cheng \& Shyu, 1995). The model has shown good consistency in accuracy in ranking with shorter rule properties where there are only five (5) rules with a minimum length of one (1) and the maximum length of three (3). In addition, the most important feature is that the developed rules have extracted the knowledge from the data input and hence are more understandable to humans (Yager, 1991).

In all cases, the satisfaction values calculated by the model are higher as compared to values obtained by Yeh and Kuo (2003). The higher value of satisfaction means the quality performance or alternatives were more satisfactory to the decision-maker. Therefore the quality evaluation done by the model is reliable (Lee, Cho \& Kwang, 1994).

The experiment on data normalization in the model was seen as significant to stabilize the input data since there are extreme values in the input data. Noise or bias in the data distribution can be diminished through data normalization which is one of the objectives of the model. The use of rules is demonstrated to be reliable as it works like human thinking and meets the goals of the assessment. The quality of a method depends on the properties of the method and the functions for which the method is designed (Zimmermann, 1980). The model had exhibited a good method where it had fulfiled three major properties: (1) formal consistency; (2) usefulness; (3) efficiency in the desired function at minimum effort, time and cost.

Table 15

Comparison of Results

\begin{tabular}{lcccc}
\hline \multirow{2}{*}{$\begin{array}{c}\text { Method } \\
\text { Airport }\end{array}$} & \multicolumn{2}{c}{ Yeh \& Kuo } & \multicolumn{2}{c}{ Proposed Model } \\
\cline { 2 - 5 } & Performance & Rank & Performance & Rank \\
\hline BKK & 0.4890 & 9 & 0.7520 & 9 \\
CGK & 0.4740 & 10 & 0.7420 & 10 \\
HKG & 0.5760 & 4 & 0.8071 & 4 \\
KIX & 0.5930 & 3 & 0.8074 & 3 \\
\hline
\end{tabular}

(continued) 
Table 15

Comparison of Results

\begin{tabular}{lcccc}
\hline \multirow{2}{*}{$\begin{array}{c}\text { Method } \\
\text { Airport }\end{array}$} & \multicolumn{2}{c}{ Yeh \& Kuo } & \multicolumn{2}{c}{ Proposed Model } \\
\cline { 2 - 5 } & Performance & Rank & Performance & Rank \\
\hline KUL & 0.5740 & 6 & 0.7979 & 6 \\
MEL & 0.5830 & 5 & 0.8030 & 5 \\
MNL & 0.3660 & 14 & 0.6536 & 14 \\
NRT & 0.5610 & 7 & 0.7881 & 7 \\
PEK & 0.4020 & 13 & 0.6676 & 13 \\
SEL & 0.4580 & 11 & 0.7079 & 11 \\
SHA & 0.4400 & 12 & 0.7024 & 12 \\
SIN & 0.6410 & 1 & 0.8656 & 1 \\
SYD & 0.6060 & 2 & 0.8397 & 2 \\
TPE & 0.5440 & 8 & 0.7630 & 8 \\
\hline
\end{tabular}

\section{CONCLUSION}

A new fuzzy evaluation model has been proposed for the evaluation of the airport services. The evaluation result can help the airport management understand their relative ranking in terms of managing the services provided to passengers. The model has been implemented using the $\mathrm{C}++$ programming language and is suitable for various fuzzy environments that involve uncertainty. The main advantage of this model is that the membership set scores are not predetermined by the expert. This is important to ensure the consistency of the decision. This was not so in the original study, whereby the fuzzy set data was constructed by the travel experts. The formulation of the similarity function and approximate reasoning of the fuzzy set theory were used to attain the set of degree of membership and ranking so that the evaluation process could be conducted consistently. The approximate reasoning of the method allows the decision maker to make the best choice in accordance with human thinking and reasoning processes.

\section{REFERENCES}

Baja, S., Chapman, D. M., \& Dragovich, D. (2002). A conceptual model for defining and assessing land management units using a fuzzy modelling approach in GIS environment. Environment Management, 29(5), 647661. 
Biswas, R. (1995). An application of fuzzy sets in student's evaluation. Fuzzy Set and Systems, 74, 187-194.

Chou, T. Y., \& G.S. Liang (2001). Application of a fuzzy multi-criteria decision-making model for shipping company performance evaluation. Maritime Policy Management, 28(4), 375-392.

Chang, Y.H., \& T. H. Shyu (1995). A fuzzy multicriteria model to evaluate the privatization of the public bus operation. Journal of Advanced Transportation, 29(1), 63-79.

Chu, F. (1990). Quantitative evaluation of university teaching quality - an application of fuzzy set and approximate reasoning. Fuzzy Sets and Systems, 37, 1-11.

Corne, S., Murray, T., Openshaw, S., See, I., \& Turton, I. (1999). Using computational intelligence techniques to model sub-glacial water systems. Journal Geograph System, 1, 37-60.

Kurtener, D., \& Badenko, V. (2000a). Methodological framework based on fuzzy sets theory for land use management. Journal of Brazil Computer Society, 6(3), 26-32.

Kurtener, D., \& Badenko, V. (2000b). Precision agriculture experimentation on the base of fuzzy models synthesized with GIS. Aspects of Applied Biology, 61, 139-143.

Lee, K. M., C. H. Cho, \& H. L. Kwang (1994). Ranking fuzzy values with satisfaction function. Fuzzy Sets and Systems, 64, 295-309.

Liang, G., \& A. Wang (1992). Personnel placement in a fuzzy environment. Computers Operations Research, 19(2), 107-121.

Muhammetoglu, A., \& Yardimci, A. (2006). A fuzzy logic approach to assess groundwater-pollution levels below agricultural fields. Environmental Monitoring and Assessment, 118, 337-354.

Othman, M., K. R. Ku-Mahamud, \&A. A. Bakar (2004a). Fuzzy rule generation using membership function. Proceeding of The $4^{\text {th }}$ Information and Computer Engineering Postgraduate Workshop. Phuket Thailand, 115120. 
Othman, M., K. R. Ku-Mahamud, \& A. A. Bakar (2004b). Fuzzy similarity function for ranking river basin planning alternatives. Proceeding of The Fifth International Workshop on Artificial Intelligence in Agricultural. Cairo, Egypt, 95-99.

Othman, M., K. R. Ku-Mahamud, \& A. A. Bakar (2004c). Ranking the river basin planning alternatives using fuzzy approximate reasoning. Chiang Mai Journal of Science, 31(2), 113-124.

Parasuraman, A., V. A. Zeithaml, \& L.L. Berry (1988). SERVQUAL: A multiple-item scale for measuring consumer perception of service quality. Journal of Retailing, 64(1), 12-40.

Pedrycz, W., \& F. Gomide (1998). An introduction to fuzzy sets analysis and design. MIT Press, Cambridge.

Singh, B., Dahiya, S., \& Jain, S. (2008). Use of fuzzy synthetic evaluation for assessment of ground water quality for drinking usage: A case study of Southern Haryana, India. Environmental Geology, 54(2), 249-255.

Sonja, P.L. (2001). Personnel selection fuzzy model. International Transactions in Operational Research, 8(1), 89-105.

Torbert, H. A., Krueger, E., \& Kurtener, D. (2008). Soil quality assessment using fuzzy modeling. International Agrophysics, 22, 365-370.

Turksen, I. B., \& I. A. Wilson (1994). A fuzzy sets preference model for consumer choice, Fuzzy Sets and Systems, 68, 253-266.

Yager, R. R. (1991). On linguistic summaries of data in knowledge discovery in databases, Piatetsky-Shapiro, G and B Frawley (Eds.), MIT Press, Cambridge, 347-363.

Yeh, C. H., \& Y. L. Kuo (2003). Evaluating passenger service of Asia-Pacific international airports. Transportation Research Part E: Logistics and Transportation Review, 39(1), 35-48.

Zhou, D., J. Ma, E. Turban, \& N. Bolloju (2002). A fuzzy set approach to the evaluation of journal grades. Fuzzy Sets and Systems, 131(1), 63-74.

Zimmermann, H. J. (1980). Testability and meaning of mathematical models in social sciences. Mathematical Model, 1, 123-139. 